\title{
The Effect of Occupational Stress and Coping Strategies on Mental Health and Emotional Well-Being Among University Academic Staff During the COVID-19 Outbreak
}

\author{
Panshuo Shen ${ }^{1} \&$ Paul Slater ${ }^{1}$ \\ ${ }^{1}$ School of Nursing, Ulster University, Belfast, UK \\ Correspondence: Panshuo Shen, School of Nursing, Ulster University, Belfast, BT37 0QB, UK. E-mail: \\ shen-p@ulster.ac.uk
}

Received: October 22, 2020

Accepted: November 28, 2020

Online Published: February 24, 2021

doi:10.5539/ies.v14n3p82

URL: https://doi.org/10.5539/ies.v14n3p82

\begin{abstract}
The level of stress among academics in higher education institutions has significantly increased over the past decade. Mental health and well-being of academics can be affected once they are exposed to stressful work conditions and use negative coping strategies. This study was set against the backdrop of the pandemic disease, COVID-19, which has challenged the daily work of academics and risen to the various new stressors. This study aims to investigate the current status of occupational stress, coping styles, mental health and emotional well-being of university academics during the COVID-19 outbreak in Northern Ireland, and examine the effect of stress and coping strategies on mental health and emotional well-being. A cross-sectional online survey was conducted using a sample size of 87 academic staff working in a university in Northern Ireland. SPSS version 25 was used to analyse the collected data. The results showed academics experienced moderate stress levels, and distraction behaviours were the most common form of coping mechanism. Academics were in the moderate status of mental health and poor emotional well-being. Occupational stress has a significant effect on mental health and emotional well-being. Positive reframing and acceptance coping styles have an impact on emotional well-being. This study contributes to the understanding of occupational stress, coping strategies, mental health and emotional well-being of academics in higher education in Northern Ireland. The findings can help to develop reliable methods to inform policy on health and well-being for university academics, which in turn lead to increased productivity at work.
\end{abstract}

Keywords: academics, coping strategies, COVID-19, mental health, occupational stress, university, well-being

\section{Introduction}

The working environment is continuously changing in today's society with globalised economies, new policies and technologies, which have led to new challenges for employees (Darus, Azizan, \& Ahmad, 2016; Jiang, Du, \& Dong, 2017). The higher education sector is among the highly influenced sectors of the changes (Terán \& Botero, 2011; Chaudhry, 2012; Vera \& González-Ledesma, 2018); it plays the role of promoting research and development as well as delivering required human capital to the country, which is vital for attaining sustainable development of economy, society, policy and technology (Lawal \& Wahab, 2011; Fernandez-Sanchez, Bernaldo, Castillejo, \& Manzanero, 2014; Adewale, Ghavifekr, \& Abdulsalam, 2017). The teaching profession in the higher education sector is one of the most stressful professions (Richards, 2012; Kataoka, Ozawa, Tomotake, Tanioka, \& King, 2014; Kang \& Sidhu, 2015; Adewale et al., 2017). More than a third of education professionals have experienced stressful work in the past academic year worldwide (The Guardian, 2019), and work stress can also lead to a financial burden on society (Skakon, Nielsen, Borg, \& Guzman, 2010; Fontinha, Easton, \&Van-Laar, 2019); most countries had a loss of $4 \%$ to $6 \%$ of GDP because of work-related health problems; the basic health services for the health problem in work cost between $\$ 18$ and $\$ 60$ per worker (World Health Organisation [WHO], 2017). In the United Kingdom (UK), there was about 217,065 staff at higher education institutions in 2018-2019 (Higher Education Statistics Agency [HSEA], 2020); according to the statistics of the Education Support (2019) in the UK, 72\% of educational professionals described themselves as stressed, and $63 \%$ considered leaving their current position. In Northern Ireland, $74 \%$ of education teachers reported stress at work, and $50 \%$ expressed the intention to leave due to the pressures on health and well-being (Education Support, 2019). 


\subsection{Occupational Stress and Coping Strategies Among Academics}

Occupational stress, which is also termed as job stress or work stress can be referred as a consequence of incongruity between demands and one's ability to cope with the situational demands within a limited time frame (De-Silva \& Samanmali, 2017; Burman \& Goswami, 2018). The levels of stress in university teachers have significantly increased over the past decade (Catano et al., 2010; Mudrak et al., 2016; Fontinha et al., 2019) because of their competing roles and multitasked responsibilities in teaching, research and publication (Sun, Wu, \& Wang, 2011; Singh, Cross, Munro, \& Jackson, 2020). The changes in the tertiary education system in the 21st century (Quraishi, Aziz, \& Siddiquah, 2018) also have increased job insecurity and increased workload for academic staff (Whitley \& Gläser, 2014; Kinman \& Wray, 2017). It was reported that $30 \%$ to $60 \%$ of academics were experiencing stress in higher education institutions and most academics experienced moderate levels of stress in the universities of China and the UK (Urbina-Garcia, 2020). Coping with the occupational stress, academic staff employed different coping strategies (Melancon, 2014); some individuals took positive approaches such as exercises, assistance and time management, the positive coping styles have helped to reduce the work stress and protect the health and well-being of academics (Iqbal \& Kokash, 2011; Fadel et al., 2019). However, others chose passive approaches such as alcohol consumption, substances misuse, smoking and unhealthy diet (Carton \& Fruchart, 2014; Ruisoto, Vaca, López-Goñi, Cacho, \& Fernández-Suárez, 2017). A survey in an American university (Holton, Barry, \& Chaney, 2016) showed the most frequently used maladaptive coping strategies by teachers as drinking alcohol and using drugs. Although using of alcohol and drug has been regarded as negative coping style, Sattler, Sauer, Mehlkop, and Graeff (2013) reported the use of drugs among academics with the aim of reducing work stress might be seen as a potentially beneficial adaption to difficulties in the modern environments. An opinion supported by Müller and Schumann (2011). However, there is a lack of research on the effect of academics' coping styles on their health and emotional well-being.

\subsection{Mental Health and Well-Being Among Academics}

Occupational stress has the most significant effect on mental health (Holton et al., 2016). A great deal of stress and health strategies in work have been implemented worldwide to combat the potential negative effects of work stress; these included the "Global Plan of Action on Workers' health 2008-2017", the "Health and Safety Executive strategy" in the UK; and the "Organisational Multi-level Program" in Australia (Urbina-Garcia, 2020). There were nearly $34 \%$ and $39 \%$ of education professionals have experienced a mental health issue in the past academic year in the UK and Northern Ireland, respectively (Education Support, 2019); 46\% and 35\% of education professionals reported anxiety and depression symptoms, respectively (Education Support, 2019). The average rates of stress, depression and anxiety for the teaching profession, which included the teachers in third level settings, were higher compared to the general workforce (Renn, 2018). The fact that $50 \%$ of educators were absent due to mental health symptoms in 2018 (Education Support, 2019), and 44\% health expenditure have been paid out on teachers' ill-health per year in the UK (Health and Safety Executive [HSE], 2019). Well-being also has become an increasingly important factor in the professional industry (Jeffrey, Mahony, Michaelson, \& Abdallah, 2014; Achour, Azmi, Isahak, Nor, \& Yusoff, 2019); it refers to how people evaluate their lives considering variables such as life satisfaction, positive emotions and lack of negative emotions (Klug \& Maier, 2015). However, to date, limited research has focused on well-being among academics in the university. Recent studies showed a decreased well-being in university teaching staff (Richards, Levesque-Bristol, Templin, \& Graber, 2016; Qudah, Davies, \& Deakin, 2019). Conversely, the quality of working life of academics at universities in Norway and Finland has been proven high, which is mainly due to the fact that the quality of life is good in general in both countries (Collinson, 2018). It is essential to investigate variables that may reduce the adverse impact on health (Darabi, Macaskill, \& Reidy, 2017) and protect academics in higher education from increasing stress and promote well-being (Aquino, Lee, Spawn, \& Bishop-Royse, 2018).

\subsection{The Theoretical Framework of the Study}

Lazarus and Folkman's (1984) model of stress and coping (Transactional Stress and Coping Theory (TTSC) (see Figure 1) is the most widely accepted theoretical framework of stress and coping (Margaret, Ngigi, \& Mutisya, 2018; Lee \& Roberts, 2018); it considers stress as a transaction between an individual and the environment (Folkman, Lazarus, Gruen, \& DeLongis, 1986). TTSC was regarded as intrapersonal processes of stress, coping and their relationship to health and well-being of individuals (Lee \& Roberts, 2018). High stress leads to ill-being and poor health concerns, especially where an individual lacks the coping resources or uses ineffective strategies to cope with stress (Lazarus \& Folkman, 1984; Hendy, Can, \& Black, 2019). TTSC provided a theoretical framework for analysing the effect of stress and coping strategies on mental health and well-being among academics (Walinga, 2010), which also provided the theoretical underpinning for the present study. 


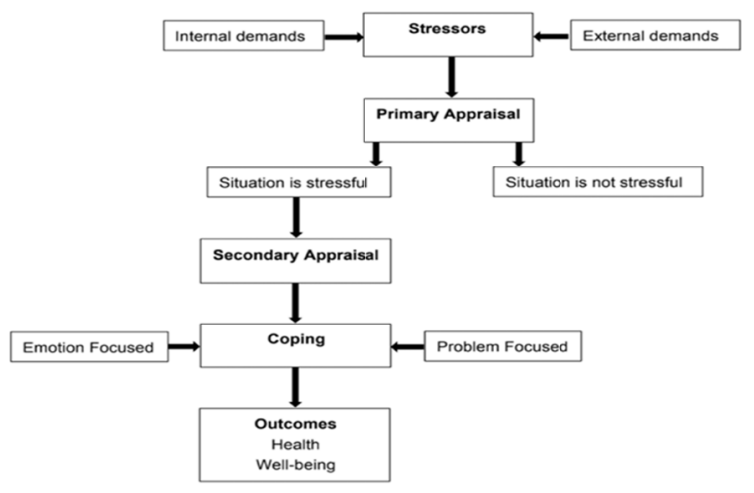

Figure 1. Transactional model of stress and coping (Lazarus \& Folkman, 1984)

\subsection{Rationale for the Study}

There are limited studies focus on the effect of occupational stress and coping mechanism on mental health and emotional well-being among academic staff in the university setting in Northern Ireland. This study focused on one of the higher education institutions in Northern Ireland and investigated the situation of occupational stress, coping strategies, mental health and emotional well-being of academic staff. It is important for institutions to recognise work-related stress, mental ill-health, and ill-being of academics. This study was set against the backdrop of the pandemic disease, novel coronavirus (nCoV) disease (COVID-19), which has been declared a public health threat globally (WHO, 2020). This pandemic has resulted in a global social and economic disruption (Islam, Ferdous, \& Potenza, 2020). Filtering down to an individual level among academics, it has challenged their daily work and risen to the various new stressors, as well as blurred the interface between work/home life distinction and balance (Li et al., 2020). This study will help provide a clear picture of the impact of these new challenges on work stress, coping strategies, and outcome measures of mental health and well-being.

\subsection{Purpose of the Study}

This study contributes to the current literature on occupational stress, coping strategies, health and emotional well-being among university academic faculty; and informs policy and strategies on improving health and well-being for university academics. The main objectives were formulated:

1) To investigate the level of occupational stress in university academic staff.

2) To inspect the coping strategies employed by academic staff to deal with stress.

3) To explore the status of mental health and emotional well-being within university academic staff.

4) To examine the relationship between occupational stress, mental health and emotional well-being along with coping strategies.

\section{Methods}

\subsection{Design and Setting}

A descriptive, cross-sectional, self-administrated questionnaire survey was conducted using a population of academic staff working in a third level education setting in Northern Ireland. This was determined and appropriate based on the advanced theoretical framework and necessary to achieve the study objectives. The study was guided by cross-sectional studies guidelines STROBE (von Elm et al., 2007).

\subsection{Sample}

The identified target population of this study was the academic staff at Ulster University in Northern Ireland, and the questionnaires were sent to all academic staff at Ulster University, an overall of 886 subjects. One hundred and ten voluntary participants returned the survey, with a response rate of $12.4 \%$. After removal of 23 questionnaires which were ineligible, a sample of 87 full-time academic staff across all departments in the university was attained. A post hoc analysis of confidence intervals showed a margin of error as $9.98 \%$.

\subsection{Procedure of Data Collection}

Data were collected through a self-reported and administered questionnaire using an online survey system (Qualtrics) from May 2020 to July 2020 at the height of the pandemic lockdown in the UK. Permission was 
sought and gained from central IT systems to distribute the questionnaire pack (participant information sheet, letter of invitation, support information and survey link) to all staff via the email system after ethical approval. Inclusion criteria were academic staff who are employed and currently working at Ulster University as full-time academics for more than 3-months as well as on the university staff emailing list. Filter questions in the introduction section of the online survey helped to ensure only the relevant staff members participating in the study. Those individuals not fulfilling these criteria were thanked for their interest and screened out when relevant. All participants also received a support sheet which signposting organisations to provide help. The research team had no access to the distribution list for the questionnaire. Completion of the questionnaire implied consent to participate in the study. Participants were assured of the confidentiality and anonymity of the data.

\subsection{Measurement Tools}

\subsubsection{Socio-Demographic Characteristics Information}

Key demographic details were collected including gender, age, marital status, number of dependents, parental role and educational level. Details regarding work such as position, employment status, work experience, and working hours per week were also be sought.

\subsubsection{Measurement of Stress}

Perceived stress scale (PSS) (Cohen \& Williamson, 1988) was used to measure the degree to which situations in one's life were appraised as stressful during the last month. It comprises 10 items which measured on a 5-point Likert scale ranging from never (0) to very often (4).

\subsubsection{Measurement of Coping Strategies}

The Brief-COPE (Carver, 1997) is a 28 item self-report questionnaire (14 subscales) designed to measure effective and ineffective ways to cope with a stressful life event. The score ranging from 1 to 4 with 1 beings 'I haven't been doing this at all' and 4 beings 'I've been doing this a lot'. An abridged version consisting of 18 items with nine subscales (active coping, substance use, emotional support, instrumental support, behavioural disengagement, positive reframing, planning, acceptance and religion) relating to coping in Covid-19 were used.

\subsubsection{Measurement of Alcohol Use}

The Alcohol Use Disorders Identification Test (AUDIT) developed by the WHO (Babor, La Fuente, Saunders, \& Grant, 1992) is used to identify persons with alcohol consumption during the past year. It comprises 10 questions that represent three conceptual domains: alcohol consumption (Items 1-3), alcohol dependence (Items 4-6), and alcohol-related consequences (Items 7-10). The total score ranges from 0 to 40, higher scores indicate a higher risk of problematic alcohol consumption. The generally accepted cut-point of the scale for identifying a potential alcohol problem is 8 (Babor \& Robaina, 2016).

\subsubsection{Measurement of Mental Health}

The Short From-12 Health Survey version 1 (SF-12v1) designed by Ware, Kosinski and Keller (1996) is widely used to assess self-reported health-related quality of life (HRQoL) within the last four weeks. Two dimensions can be derived from the SF-12, including a Mental Component Summary (MCS) and a Physical Component Summary (PCS) (Damásio, Andrade, \& Koller, 2015). The SF-12 summary scores (PCS and MCS) ranged from 0 to 100 , a zero score indicates the lowest level of mental health and 100 indicates the highest level of mental health (Shou et al., 2016). This study used subscale-MCS (6 items) to explore the status of mental health among academics.

\subsubsection{Measurement of Emotional Well-being}

The satisfaction with life scale (SWLS) originally developed by Diener, Emmons, Larsen, and Griffin (1985) was designed to measure global cognitive judgements of satisfaction with life. This scale consists of 5 items measured on a 7 -point scale that ranges from 7 strongly agree to 1 strongly disagree; higher scores on the SWLS mean greater levels of life satisfaction.

\subsubsection{Validity and Reliability of Scales}

An expert panel consisted of 5 academic staff from the faculty leading the research in the university examined the validity of the instruments before distribution electronically. Cronbach's alpha coefficients of each scale were greater than 0.7 (see Table 1), indicating that the measurement tools employed in the present study had reasonable internal consistency reliability. 
Table 1. Reliability analysis

\begin{tabular}{lcc}
\hline Scale & No of Items & Cronbach's Alpha \\
\hline Perceived Stress Scale (PSS) & 10 & 0.91 \\
Brief COPE Scale & 18 & 0.83 \\
Alcohol Use Disorders Identification Test (AUDIT) & 10 & 0.74 \\
The Short Form Health Survey (SF) & 6 & 0.81 \\
Satisfaction with Life Scale (SWLS) & 5 & 0.92 \\
\hline
\end{tabular}

\subsection{Ethical Considerations}

This study was approved by the Nursing and Health Science Filter Committee of Ulster University and Ethics Committee of Ulster University, and the study was carried out in accordance with the ethical standards. Participants were informed about the information of the study, and their rights to participate and withdraw during the research. Confidentiality and anonymity were ensured by informing the participants that completing the questionnaire implies their consent. All participants were provided with a support sheet which signposting organisations to provide help. The collected data were only used for the research purpose and were protected properly by obeying protection legislation and Ulster University policy.

\subsection{Statistical Analysis}

Statistical Package for the Social Sciences (SPSS) was used to analyse the collected data. Descriptive statistics were used to summarise the feature of the demographic data and examine the normality of distribution. Cronbach's alpha coefficients were used to test the internal consistency reliability of each scale before summation to a total score. Linear regression analysis includes model fitness, and regression coefficients were used to determine the significance of differences of sociodemographic variables (such as age, gender, work experience and position), stress, coping strategies (active coping, substance using, emotional support, instrumental support, behavioural disengagement, positive reframing, planning, acceptance and religion), mental health and emotional well-being. For all the tests conducted, a p-value of $\leq 0.05$ is considered statistically significant. The analysis was guided by the TTSC, and coping mechanisms were examined as moderating variables between stress and well-being measures.

\section{Results}

\subsection{Response Rate}

A total of 886 questionnaires were issued, and 110 voluntary participants returned the survey, yielding a response rate of $12.4 \%$. After removal of 23 ineligible questionnaires, 87 effective questionnaires were obtained, with effective response rate at $9.8 \%$.

\subsection{Sociodemographic Characteristics}

The basic characteristics of the respondents were shown in Table 1. Respondents included 55 (63.2\%) females. Most of the respondents $(79.3 \%, \mathrm{n}=69)$ were married or cohabitation. The majority $(35.6 \%, \mathrm{n}=31)$ of them age ranged from 45 to 54 ; and $28.7 \%(\mathrm{n}=25)$ reported age ranged from 55-65. A large number of respondents had Doctor degree $(64.4 \%, n=56)$. In terms of academic rank, $63.2 \%(n=55)$ were lecturers and $35.6 \%(n=31)$ were senior lecturer and above, with $93.1 \%(\mathrm{n}=81)$ in permanent post and $6.9 \%(\mathrm{n}=6)$ in fixed position. Majority of respondents were from the "Life and Health Sciences School" (50.6\%, $n=44)$. Most respondents $(32.2 \%, n=28)$ have worked for $1-5$ years in the university, $17.2 \%(n=15)$ had $21-30$ years' working experience, with a large number of respondents had a workload of 41-50 hours per week which accounting for $37.9 \%(n=33)$ of the questionnaires. The characteristics of dependents and home-schooling involvement were presented in Table 2 . 
Table 2. Sociodemographic characteristics of the study participants

\begin{tabular}{|c|c|c|c|}
\hline Variable & & Frequency & Percent $(\%)$ \\
\hline \multirow{2}{*}{ Age } & $25-34$ & 9 & 10.3 \\
\hline & $35-44$ & 22 & 25.3 \\
\hline Gender & Male & 32 & 36.8 \\
\hline \multirow{2}{*}{ Marital status } & Single/divorced/separated & 17 & 19.5 \\
\hline & Missing & 1 & 1.1 \\
\hline Educational level & Masters and below & 31 & 35.6 \\
\hline \multirow{4}{*}{ Dependents under 18 years old } & 0 & 42 & 48.3 \\
\hline & 1 & 14 & 16.1 \\
\hline & 2 & 20 & 23.0 \\
\hline & $\geq 3$ & 11 & 12.6 \\
\hline \multirow{4}{*}{ Involving in dependents' home-schooling (hours/per day) } & $<1$ & 45 & 51.7 \\
\hline & $1-2$ & 15 & 17.2 \\
\hline & $\geq 3$ & 23 & 26.4 \\
\hline & Missing & 4 & 4.6 \\
\hline
\end{tabular}

\subsection{Occupational Stress}

Most academics (66.7\%) experienced moderate stress, and 16.1\% with high stress level during the COVID-19 outbreak, with mean (SD) stress score was 19.78 (7.44) (see Table 3). Overall socio-demographic factors were not significantly associated with stress $(\mathrm{F}=1.350, \mathrm{P}=0.228)$ using multiple regression analysis (see Table 4). Coefficients analysis justified the individual effect of the independent variables, which also showed the individual socio-demographic factor had no significant association with stress among academics and were poor predictors of the model.

Table 3. Stress level of academics

\begin{tabular}{cccc}
\hline Stress Level & Frequency & Percent (\%) & Mean (SD) \\
\hline Low & 15 & 17.2 & \\
Moderate & 58 & 66.7 & \\
High & 14 & 16.1 & \\
Total & 87 & 100 & \\
Stress Score & & & $19.78(7.44)$ \\
\hline
\end{tabular}

Table 4. Association between stress and socio-demographic factors of academics

\begin{tabular}{ccccc}
\hline Model & R & Adjusted R Square & F & P \\
\hline 1 & $0.385^{\text {a }}$ & 0.038 & 1.350 & 0.228 \\
\hline
\end{tabular}

Note. a. Predictors: (Constant), socio-demographic factors (i.e. gender, age, marital status)

\subsection{Coping Strategies}

Coping styles of academics were summarised in Table 5. Instrumental support and religion were shown in low score among these coping strategies. After recoding the negative coping styles, the mean score of substance using and behavioural disengagement was high, which means academics less relied on substance and disengagement to cope with stress. Distraction behaviours were the most common form of coping mechanism. Using multiple regression analysis, the overall model of socio-demographic factors and behavioural disengagement was not statistically significant $(\mathrm{F}=1.275, \mathrm{P}=0.268)$. The regression of coefficient further explored the individual impact of the independent variable, socio-demographic factors, which showed that working hours and behavioural disengagement of academics have a significantly negative relationship $(\beta=-0.279, \mathrm{P}=0.033)$. Positive reframing and acceptance coping styles both have a positive and significant relation with dependents of academics $(\beta=0.512, \mathrm{P}=0.003 ; \beta=0.536, \mathrm{P}=0.005$ respectively). Other coping strategies have no significant relation to socio-demographic factors. 
Table 5. Coping styles of academics

\begin{tabular}{cc}
\hline Coping Strategies & Mean (SD) \\
\hline Religion & $3.35(1.69)$ \\
Instrumental support & $3.44(1.44)$ \\
Emotional support & $4.11(1.62)$ \\
Active coping & $5.00(1.93)$ \\
Planning & $5.00(1.92)$ \\
Positive reframing & $5.10(1.68)$ \\
Acceptance & $5.79(1.82)$ \\
Substance using & $7.08(1.29)$ \\
Behavioural disengagement & $7.16(1.08)$ \\
\hline
\end{tabular}

Most academics (78.2\%) had a low risk of alcohol dependence and 19.5\% academics had an increasing risk of alcohol dependence. Academics with high risk and possible alcohol dependence only took $2.2 \%$. Mean (SD) alcohol use score was 4.98 (4.04) (see Table 6). The relation of socio-demographic factors and alcohol use among academics was not statistically significant $(\mathrm{F}=1.450, \mathrm{P}=0.184)$

Table 6. Alcohol dependence risk category of academics

\begin{tabular}{cccc}
\hline Risk category & Frequency & Percent $(\%)$ & Mean (SD) \\
\hline Low risk & 68 & 78.2 & \\
Increasing risk & 17 & 19.5 & \\
High risk/Possible dependence & 2 & 2.2 & \\
Total & 87 & 100.0 & \\
Alcohol use Score & & & $4.98(4.04)$ \\
\hline
\end{tabular}

\subsection{Predicting Mental Health}

The average status of mental health among university academics during the COVID-19 outbreak was in moderate level with the mean score (SD) was 50.79 (25.64). Socio-demographic variables and mental health showed no significant association $(\mathrm{F}=0.825, \mathrm{P}=0.596)$. Stress as a predictor in the regression analysis produced a statistically significant model $(\mathrm{F}=72.725, \mathrm{P}=0.001)$, accounting for approximately $48.2 \%$ of the variance in the mental health of academics. There was a significantly negative relationship between stress and mental health, which indicated higher levels of stress $(\beta=-0.699, \mathrm{t}=-8.528, \mathrm{P}=0.001)$ predicted poor mental health (see Table 7). The entry of the ten coping strategies in the regression analysis resulted in a not statistically significant model $(\mathrm{F}=8.090, \mathrm{P}=0.594)$, each coping style had no significant relationship with the mental health of academics.

Table 7. Regression analysis with mental health as dependent variable and stress as predictor

\begin{tabular}{|c|c|c|c|c|c|c|c|}
\hline \multirow[t]{2}{*}{ Predictors } & \multicolumn{2}{|c|}{$\begin{array}{c}\text { Unstandardized } \\
\text { Coefficients }\end{array}$} & \multirow{2}{*}{$\begin{array}{c}\text { Standardised coefficients } \\
\text { Beta }\end{array}$} & \multirow[t]{2}{*}{$\mathrm{t}$} & \multirow[t]{2}{*}{$P$} & \multirow[t]{2}{*}{ F } & \multirow[t]{2}{*}{ Adjusted R Square } \\
\hline & $\mathrm{B}$ & $\mathrm{SE}$ & & & & & \\
\hline (Constant) & 1.359 & 0.172 & & 7.906 & 0.000 & 72.725 & 0.482 \\
\hline Stress & -0.690 & 0.081 & -0.699 & -8.528 & 0.000 & & \\
\hline
\end{tabular}

\subsection{Predicting Emotional Well-being}

Most participants reported poor emotional well-being during the COVID-19 outbreak with a mean (SD) score of 16.28 (7.46). $35.6 \%$ of academics showed dissatisfaction with life and $11.5 \%$ extremely dissatisfied, only $13.8 \%$ satisfied and $3.4 \%$ extremely satisfied with life. Socio-demographic variables and emotional well-being had no significant relations $(\mathrm{F}=0.760, \mathrm{P}=0.653)$. Stress as a predictor in the regression analysis produced a statistically significant model $(\mathrm{F}=27.749, \mathrm{P}=0.004)$, accounting for approximately $25.8 \%$ of the variance in the emotional well-being of academics. There was a significant relationship between stress and the emotional well-being ( $\beta=$ $0.517, \mathrm{t}=5.268, \mathrm{P}=0.000<0.05$ ) (see Table 8 ). The entry of the coping strategies in the regression analysis resulted in a statistically significant model $(\mathrm{F}=5.222, \mathrm{P}=0.004)$, accounting for approximately $37.6 \%$ of the 
variance in the emotional well-being of academics (see Table 9). Specifically, positive reframing and acceptance coping styles were significant predictors of emotional well-being $(\beta=-0.236, \mathrm{t}=-1.934, \mathrm{P}=0.002 ; \beta=-0.134, \mathrm{t}=$ -1.082, $\mathrm{P}=0.032$ ) (see Table 9).

Table 8. Regression analysis with well-being as dependent variable and stress as predictor

\begin{tabular}{|c|c|c|c|c|c|c|c|}
\hline \multirow[t]{2}{*}{ Predictors } & \multicolumn{2}{|c|}{$\begin{array}{c}\text { Unstandardized } \\
\text { Coefficients }\end{array}$} & \multirow[t]{2}{*}{$\begin{array}{c}\text { Standardised coefficients } \\
\text { Beta }\end{array}$} & \multirow[t]{2}{*}{$\mathrm{t}$} & \multirow[t]{2}{*}{$\mathrm{P}$} & \multirow[t]{2}{*}{$\mathrm{F}$} & \multirow[t]{2}{*}{ Adjusted R Square } \\
\hline & $\mathrm{B}$ & SE & & & & & \\
\hline (Constant) & 1.226 & 0.412 & & 2.975 & 0.004 & 27.749 & 0.258 \\
\hline Stress & 1.023 & 0.194 & 0.517 & 5.268 & 0.000 & & \\
\hline
\end{tabular}

Table 9. Regression analysis with well-being as dependent variable and coping styles as predictor

\begin{tabular}{|c|c|c|c|c|c|c|c|}
\hline \multirow[t]{2}{*}{ Predictors } & \multicolumn{2}{|c|}{$\begin{array}{c}\text { Unstandardized } \\
\text { Coefficients }\end{array}$} & \multirow{2}{*}{$\begin{array}{c}\text { Standardised coefficients } \\
\text { Beta }\end{array}$} & \multirow[t]{2}{*}{$\mathrm{t}$} & \multirow[t]{2}{*}{$\mathrm{P}$} & \multirow[t]{2}{*}{$\mathrm{F}$} & \multirow[t]{2}{*}{ Adjusted R Square } \\
\hline & $\mathrm{B}$ & SE & & & & & \\
\hline (Constant) & 5.206 & 1.779 & & 2.975 & 0.004 & 5.222 & 0.376 \\
\hline Active Coping & 0.359 & 0.198 & 0.231 & 1.814 & 0.895 & & \\
\hline Substance Using & -0.073 & 0.307 & -0.032 & -0.237 & 0.422 & & \\
\hline Emotional Support & -0.414 & 0.260 & -0.230 & -1.597 & 0.105 & & \\
\hline Instrumental Support & 0.254 & 0.304 & 0.130 & 0.833 & 0.823 & & \\
\hline Behavioural Disengagement & -0.546 & 0.309 & -0.196 & -1.767 & 0.057 & & \\
\hline Positive Reframing & -0.419 & 0.217 & -0.236 & -1.934 & 0.002 & & \\
\hline Planning & -0.014 & 0.258 & -0.009 & -0.055 & 0.159 & & \\
\hline Acceptance & -0.221 & 0.204 & -0.134 & -1.082 & 0.032 & & \\
\hline Religion & -0.218 & 0.174 & -0.123 & -1.252 & 0.059 & & \\
\hline Alcohol Use & 0.218 & 0.437 & 0.061 & 0.498 & 0.413 & & \\
\hline
\end{tabular}

\section{Discussion}

This study investigated the current status of occupational stress, coping styles, mental health and emotional well-being of university academics, and examined the effect of stress and coping strategies on mental health and emotional well-being through the lens of TTSC. It was found that academics experienced moderate stress during the COVID-19 outbreak. This stress level was lower than the stress level of previous findings in developing countries such as China (Li \& Kou, 2018), India (Priyadarshini, Ponnam, \& Banerjee, 2015) and Brazil (Tavares et al., 2012), but it was similar to the findings in Australian university (Bell, Rajendran, \& Theiler, 2012) and other universities in the UK (Kinman, 2016). These findings suggest that the academic environment and outside environment in different countries can impact the academics differently. Socio-demographic factors did not affect stress in this study. Similarly, a study in a public university in Brazil (Fadel et al., 2019) also found no demographic condition had shown a significant relationship with stress. However, a survey of 5,445 academic staff in 56 Canadian universities found that female academics have more risk of stress compared to male faculty. This was also reported in Fontinha et al.'s (2019) study that women showed significantly higher levels of stress at work in a sample of 1,474 academics in nine British higher education institutions. Some findings also revealed academics who aged from 36 to 45 (Catano et al., 2010; Li \& Kou, 2018), in an assistant professor position (Tavares et al., 2012; Meng \& Wang, 2018) and working over ten years (Meng \& Wang, 2018) in the institution were likely to report a higher level of psychological stress.

Most of the academics in this study employed positive coping styles to deal with occupational stress during the COVID-19 outbreak, which including emotional support, active coping, planning, positive reframing and acceptance. Adaptive coping styles were used by academics in most previous studies. Problem-focused coping was more likely to be used to manage stress by academics according to the study conducted by Darabi et al. (2017) in a British university. Priyadarshini et al. (2015) conducted an in-depth interview also found that academics in the universities in India were enjoying the work through a positive cognitive appraisal. Negative coping styles among academics, such as the high level of alcohol consumption were few in this study. Conversely, alcohol drinking as a coping behaviour for stressful conditions was used by $82 \%$ of professors in a private university in Spain (Ruisoto et al., 2017), with 13.1\% reported problematic alcohol consumption. Ruisoto 
et al. (2017) found that male professors were more likely to have alcohol drinking for stress coping than female professors. The present study found no gender difference in alcohol use, but it found that long working hours had an impact on behavioural disengagement coping style, and dependents of academics contributed to positive reframing and acceptance coping styles. There are no literature has the same finding with the present study, which need to be further explored.

In terms of mental health, academics were in the moderate status of mental health in the study. A study conducted in a Chinese university showed $43 \%$ of academics were in not good or even poor mental health (Li \& Kou, 2018). Khan, Yusoff, and Isa (2016) investigated stress related mental health problems among 1,189 academic staff members in 12 universities in Pakistan, the results showed that $50 \%$ academics experienced a mild level of anxiety, $49 \%$ had social dysfunction and depression symptoms. There was no significant difference between socio-demographic characteristics and mental health of academics in this study. This result was consistent with Darabi et al.'s (2017) study among academics in the UK. Gender difference in mental health was reported by Catano et al. (2010), which showed female academics reported more physical and psychological health issues than male faculty. Professors were found had a lower level of mental disorders than other academic ranks in Khan et al. (2016) and Shen et al.'s (2014) studies. Occupational stress has a significant effect on mental health in this study. This also supported by Catano et al. (2010) and Kinman (2016), they found high levels of stress at work among academics were related to greater levels of mental health problem. The study among Chinese academics also found that occupational stress was positively associated with depressive symptoms. Coping strategies were found not significantly related to the mental health of academics in this study. A study conducted by Darabi et al. (2017) found that emotion-focused coping has no relationship with mental health while the problem-focused coping style was positively associated with mental health.

This study showed academics were in poor emotional well-being during the COVID-19 outbreak. This result was same with the study in Canadian universities, academics reported a decreased positivity towards their well-being in higher education institution (Catano et al., 2010). A study in an Indian university (Sawhney \& Bansal, 2013) and a study in Australian universities (Bell et al., 2012) found college teachers had an average life satisfaction level and low levels of ill-being (Sawhney \& Bansal, 2013). Socio-demographic factors were found did not affect the well-being of academics in the present study. However, Fontinha et al. (2019) found male faculty was likely to express higher levels of positive well-being than female faculty. Academics with tenure track in British universities were more likely to have poorer emotional well-being than temporary workers (Fontinha et al., 2019). Occupational stress has a significant effect on the well-being of university academics. This was supported by Bell et al. (2012) and Sawhney and Bansal (2013), they found that occupational stress was negatively related to well-being, which indicates a higher level of work stress did lead to poorer well-being among academic faulty. Positive reframing and acceptance coping styles significantly influenced the emotional well-being of academics in the present study. Darabi et al. (2017) also found problem-focused and emotional-focused coping styles were positively associated with the well-being of academics (Darabi et al., 2017).

\section{Limitations and Strengths}

This study contributed to the current understanding of occupational stress, coping strategies, health and emotional well-being among academics in higher education. Despite the strengths of the study, some limitations need to be considered. The participants were from one university, which made sample representativeness and difficult to generalise the results to a wider population. The response rate was low in the present study, which cannot fully explore statistically significant relations between the investigated variables. Larger sample size and powerful respondent rate may give better result and interpretation; therefore, future research should expand the sample size and the sample can across different higher education settings. The cross-sectional correlational data of the stress, coping, health and well-being of university academics in the study cannot reveal the dynamic changes of the effect of occupational stress and coping strategies on mental health and emotional well-being among academics, and the direction of causality cannot be established. In the future study, employing a longitudinal design would be practical to track the dynamic changes and avoid the limitation of cross-sectional data. Depending on different scales to measure stress and coping strategies, more aspects of stress experience and coping styles in work cannot be explored from the subjective perception of academics, an in-depth interview with selected participants would help understand the issues at hand. The scope of this research is limited as it cannot dissociate COVID-19 impact with academic stress; and this study only explored the effect of occupational stress and coping strategies on mental health and emotional well-being of academics. The source of stress and relation between stress and coping styles can be explored in the future study to enrich the research. 


\section{Recommendation}

Addressing occupational stress can improve health and well-being in academics, which also can lead to increased productivity and efficiency in work (Dehnad et al., 2016). Implementing interventions and policy to reduce stress is necessary. Universities should address attention on academics' health and well-being over profits; creating a comfortable work environment for university teachers to improve their performance in work (Fadel et al., 2019); and organising workshops, programme and activities for enhancing counsel, advise and negotiation skills (Iqbal \& Kokash, 2011). Besides, employers should care for workers and give adequate resource and support in their work. At the government level, the Higher Education Commission in Northern Ireland should invest to the development of higher education institutions; and legislation should be designed related to work stress, health, safety and benefits of teachers (Khan et al., 2016). More researches also should be conducted to further explore the dynamic changes of occupational stress, coping strategies as well as mental health and emotional well-being among academics in higher education institutions, and the relationship between stress and coping strategies.

\section{Conclusion}

This study contributed to the current understanding of occupational stress, coping strategies, mental health and emotional well-being of academics in higher education in Northern Ireland. The results of the present study were suggestive due to the limitations of the study. Academics experienced moderate stress during the COVID-19 outbreak, and distraction behaviours were the most common form of the coping mechanism among academics in dealing with occupational stress. In terms of mental health and emotional well-being, academics were in the moderate status of mental health and poor emotional well-being. Occupational stress has a significant effect on mental health and emotional well-being of university academics. Positive reframing and acceptance coping styles significantly influenced emotional well-being among academics. The findings can help to develop reliable methods to inform policy on health and well-being for university academics, which in turn lead to increased productivity at work.

\section{References}

Achour, M., Azmi, I. B. A. G., Isahak, M.B., Nor, M. R. M., \& Yusoff, M. Y. Z. M. (2019). Job stress and nurses' well-being: Prayer and age as moderators. Community Mental Health Journal, 55(7), 1226-1235. https://doi.org/10.1007/s10597-019-00410-y

Adewale, A. S., Ghavifekr, S., \& Abdulsalam, I. (2017). Impact of stress on academic staff: Implication for higher education management and leadership. Malaysian Online Journal of Educational Management, 5(2), 75-91. https://doi.org/10.22452/mojem.vol5no2.5

Aquino, E., Lee, Y.-M., Spawn, N., \& Bishop Royse, J. (2018). The impact of burnout on doctorate nursing faculty's intent to leave their academic position: A descriptive survey research design. Nurse Education Today, 69, 35-40. https://doi.org/10.1016/j.nedt.2018.06.027

Babor, T. F., La Fuente, J. R., Saunders, J., \& Grant, M. (1992). AUDIT, the Alcohol Use Disorders Identification Test: guidelines for use in primary health care. Geneva: Substance Abuse Department, World Health Organization, WHO/PSA, 4, 1-29. Retrieved from https://apps.who.int/iris/bitstream/handle/10665/67205/ WHO_MSD_MSB_01.6a.pdf;jsessionid=64CDCD5F86E85CDAE692D4FC49854635? sequence=1

Babor, T.F., \& Robaina, K. (2016). The Alcohol Use Disorders Identification Test (AUDIT): A review of graded severity algorithms and national adaptations. The International Journal of Alcohol and Drug Research, 5(2), 17-24. https://doi.org/10.7895/ijadr.v5i2.222

Bell, A.S., Rajendran, D., \& Theiler, S. (2012). Job Stress, Wellbeing, Work-Life Balance and Work-Life Conflict Among Australian Academics. E-Journal of Applied Psychology, 8(1), 25-37. https://doi.org/10.7790/ejap.v8i1.320

Burman, R., \& Goswami, T. G. (2018). A systematic literature review of work stress. International Journal of Management Studies, 5(3-9), 112-132. https://doi.org/10.18843/ijms/v5i3(9)/15

Carton, A., \& Fruchart, E. (2014). Sources of stress, coping strategies, emotional experience: Effects of the level of experience in primary school teachers in France. Educational Review, 66(2), 245-262. https://doi.org/10.1080/00131911.2013.769937

Carver, C. S. (1997). You want to measure coping but your protocol's too long: Consider the Brief COPE. $\begin{array}{llll}\text { International Journal of Behavioural } & \text { Medicine, }\end{array}$ https://doi.org/10.1207/s15327558ijbm0401_6 
Catano, V. M., Francis, L., Haines, T., Kirpalani, H., Shannon, H., Stringer, B., \& Lozanski, L. (2010). Occupational stress in Canadian universities: A national survey. International Journal of Stress Management, 17(3), 232-258. https://doi.org/10.1037/a0018582

Chaudhry, A. Q. (2012). The Relationship between Occupational Stress and Job Satisfaction: The Case of Pakistani Universities. International Education Studies, 5(3), 212-221. https://doi.org/10.5539/ies.v5n3p212

Cohen, S., \& Williamson, G. (1988). Perceived stress in a probability sample of the United States. Social Psychology of Health, 31-67. Retrieved from https://psycnet.apa.org/record/1988-98838-002

Collinson, P. (2018). Finland is the happiest country in the world, says UN report. Retrieved from https://www.theguardian.com/world/2018/mar/14/finland-happiest-country-world-un-report

Damásio, B. F., Andrade, T. F., \& Koller, S. H. (2015). Psychometric Properties of the Brazilian 12-Item Short-Form Health Survey Version 2 (SF-12v2). Paidéia (Ribeirão Preto), 25(60), 29-37. https://doi.org/10.1590/1982-43272560201505

Darabi, M., Macaskill, A., \& Reidy, L. (2017). Stress among UK academics: Identifying who copes best. Journal of further and Higher Education, 41(3), 393-412. https://doi.org/10.1080/0309877X.2015.1117598

Darus, A., Azizan, F. L., \& Ahmad, F. (2016). Work stress, pay satisfaction, psychological empowerment and organisational commitment among academic staff. International Journal of Management Studies, 23(1), 51-72. https://doi.org/10.32890/ijms.23.1.2016.10466

De Silva, N., Samanmali, R., \& De Silva, H. L. (2017). Managing occupational stress of professionals in large construction projects. Journal of Engineering, Design and Technology, 15(4), 488-504. https://doi.org/10.1108/JEDT-09-2016-0066

Dehnad, S. V., Ghoreishizadeh, M. A.G. A., Falsefi, P., Negahdari, R., \& Babalou, A.R. (2016). The Comparison of Job Stress among Dental Professionals of Dentistry Faculty Members of Tabriz University. Asian Journal of Pharmaceutical Research and Health Care, 8(S1), 7-11. https://doi.org/10.18311/ajprhc/2016/7714

Diener, E., Emmons, R. A., Larsen, R. J., \& Griffin, S. (1985). The Satisfaction with Life Scale. Journal of Personality Assessment, 49, 71-75. https://doi.org/10.1207/s15327752jpa4901_13

Education Support. (2019). Teacher wellbeing index 2019. Retrieved from https://www.educationsupport.org.uk/sites/default/files/teacher_wellbeing_index_2019.pdf

Fadel, C.B., Flores, M.T., Brigola, S., Zanesco, C., Bordin, D., \& de Souza Martins, A. (2019). Work process and disposal of stress between teachers of biological sciences and health. Revista De Pesquisa: Cuidado é Fundamental Online, 11(4), 836-841. http://dx.doi.org/10.9789/2175-5361.2019.v11i4.836-841

Fernandez-Sanchez, G., Bernaldo, M. O., Castillejo, A., \& Manzanero, A. M. (2014). Education for sustainable development in higher education: State of the art, barriers and challenges. Higher Learning Research Communications, 4(3), 3-11. https://doi.org/10.18870/hlrc.v4i3.157

Folkman, S., Lazarus, R. S., Gruen, R.J., \& DeLongis, A. (1986). Appraisal, coping, health status, and psychological symptoms. Journal of Personality and Social Psychology, 50(3), 571-579. https://doi.org/10.1037/0022-3514.50.3.571

Fontinha, R., Easton, S., \& Van Laar, D. (2019). Overtime and quality of working life in academics and non-academics: The role of perceived work-life balance. International Journal of Stress Management, 26(2), 173. https://doi.org/10.1037/str0000067

Health and Safety Executive (HSE). (2019). Work-related stress, anxiety or depression statistics in Great Britain 2019. Retrieved from https://www.hse.gov.uk/statistics/causdis/stress.pdf

Hendy, H. M., Can, S. H., \& Black, P. (2019). Workplace Deviance as a Possible "Maladaptive Coping" Behavior Displayed in Association with Workplace Stressors. Deviant Behavior, 40(7), 791-798. https://doi.org/10.1080/01639625.2018.1441684

Higher Education Statistics Agency. (HSEA). (2020). Higher education staff statistics: UK, 2018/19. Retrieved from https://www.hesa.ac.uk/news/23-01-2020/sb256-higher-education-staff-statistics\#: :text=In\%20201 8\%2F19\%2C\%2098\%2C600\%2C,was\%20100\%2C120\%2C\%20or\%2047\%25

Holton, M. K., Barry, A. E., \& Chaney, J. D. (2016). Employee stress management: An examination of adaptive and maladaptive coping strategies on employee health. Work, 53(2), 299-305. https://doi.org/10.3233/WOR-152145 
Iqbal, A., \& Kokash, H. (2011). Faculty perception of stress and coping strategies in a Saudi Private University: An exploratory study. Journal of International Education Studies, 4(3), 137-149. https://doi.org/10.5539/ies.v4n3p137

Islam, M. S., Ferdous, M. Z., \& Potenza, M. N. (2020). Panic and generalized anxiety during the COVID-19 pandemic among Bangladeshi people: An online pilot survey early in the outbreak. Journal of Affective Disorders, 276, 30-37. https://doi.org/10.1016/j.jad.2020.06.049

Jeffrey, K., Mahony, S., Michaelson, J., \& Abdallah, S. (2014). Well-being at work: A review of the literature. Retrieved from https://neweconomics.org/2014/03/wellbeing-at-work

Jiang, X., Du, J., \& Dong, R. (2017). Coping style, job burnout and mental health of university teachers of the millennial generation. Eurasia Journal of Mathematics, Science and Technology Education, 13(7), 3379-3392. https://doi.org/10.12973/eurasia.2017.00734a

Kang, L. S., \& Sidhu, H. (2015). Identification of stressors at work: A study of university teachers in India. Global Business Review, 16(2), 303-320. https://doi.org/10.1177/0972150914564421

Kataoka, M., Ozawa, K., Tomotake, M., Tanioka, T., \& King, B. (2014). Occupational stress and its related factors among university teachers in Japan. Health, 6, 299-305. https://doi.org/10.4236/health.2014.65043

Khan, A., Yusoff, R. B. M., \& Isa, K.B. (2016). Examining Linkages between Psychological Health Problems, Socio-Demographic Characteristics and Workplace Stressors in Pakistan's Academia. International Education Studies, 9(6), 108-119. https://doi.org/10.5539/ies.v9n6p108

Kinman, G. (2016). Effort-reward imbalance and overcommitment in UK academics: implications for mental health, satisfaction and retention. Journal of Higher Education Policy and Management, 38(5), 504-518. https://doi.org/10.1080/1360080X.2016.1181884

Kinman, G., \& Wray, S. (2017). Work-related wellbeing in UK higher education. https://doi.org/10.13140/RG.2.2.24867.76321

Lawal, N. A., \& Wahab, T. I. (2011). Education and economic growth: The Nigerian experience. Journal of Emerging Trends in Economics and Management Sciences, 2(3), 225-231. Retrieved from https://hdl.handle.net/10520/EJC134170

Lazarus, R. S., \& Folkman, S. (1984). Stress, appraisal, and coping. New York, NY: Springer.

Lee, E., \& Roberts, L. J. (2018). Between individual and family coping: a decade of theory and research on couples coping with health-related stress. Journal of Family Theory \& Review, 10(1), 141-164. https://doi.org/10.1111/jftr.12252

Li, Q., Miao, Y., Zeng, X., Tarimo, C. S., Wu, C., \& Wu, J. (2020). Prevalence and Factors for Anxiety during the Coronavirus Disease 2019 (COVID-19) Epidemic among the Teachers in China. Journal of Affective Disorders, 13(6), 1-21. https://doi.org/10.1016/j.jad.2020.08.017

Li, W., \& Kou, C. (2018). Prevalence and correlates of psychological stress among teachers at a national key comprehensive university in China. International Journal of Occupational and Environmental Health, 24(1-2), 7-16. https://doi.org/10.1080/10773525.2018.1500803

Margaret, K., Ngigi, S., \& Mutisya, S. (2018). Sources of occupational stress and coping strategies among teachers in borstal institutions in Kenya. Edelweiss Psyc Open Access, 2, 18-21. https://doi.org/10.33805/2638-8073.111

Melancon, R. R. (2014). Stress and the Psychological Well-Being of Organizational Leaders: A Qualitative Inquiry Into the Coping Strategies Used by School Administrators (Doctoral dissertation). Available from ProQuest Dissertation \& Theses: Full Text (NR3687698).

Meng, Q., \& Wang, G. (2018). A research on sources of university faculty occupational stress: a Chinese case study. Psychology Research and Behavior Management, 11, 597. https://doi.org/10.2147/PRBM.S187295

Mudrak, J., Zabrodska, K., Kveton, P., Jelinek, M., Blatny, M., Solcova, I., \& Machovcova, K. (2016). Occupational well-being among university faculty: A job demand resources model. Research in Higher Education, 59, 325-348. https://doi.org/10.1007/s11162-017-9467-x

Müller, C. P., \& Schumann, G. (2011). Drugs as instruments: A new framework for non-addictive psychoactive drug use. Behavioral and Brain Sciences, 34, 293-310. https://doi.org/10.1017/S0140525X11000057

Priyadarshini, C., Ponnam, A., \& Banerjee, P. (2015). Role Stress and Coping Among Business School 
Professors: A Phenomenological Study. Qualitative Report, 20(12), 2050-2066. Retrieved from https://www.researchgate.net/profile/Chetna_Priyadarshini/publication/283726610_Role_stress_and_Copin g_among_Business_School_Professors_A_Phenomenological_Study/links/5680cfdf08ae1e63fle $9 \mathrm{f} 43 \mathrm{~d}$.pdf

Qudah, S., Davies, J., \& Deakin, R. (2019). Can we get more satisfaction? Improving quality of working life survey results in UK universities. Perspectives: Policy and Practice in Higher Education, 23(2-3), 39-47. https://doi.org/10.1080/13603108.2018.1534758

Quraishi, U., Aziz, F., \& Siddiquah, A. (2018). Stress and coping strategies of university teachers in Pakistan. Pakistan Journal of Education, 35(2), 193-206. https://doi.org/10.30971/pje.v35i2.550

Renn, C. (2018). Teacher Wellbeing Index 2018 highlights stress epidemic and rising mental health issues across the sector. Retrieved from https://www.educationsupport.org.uk/about-us/press-centre/teacher-wellbeing -index-2018-highlights-stress-epidemic-and-rising-mental

Richards, J. (2012). Teacher stress and coping strategies: A national snapshot. The Educational Forum, 76(3), 299-316. https://doi.org/10.1080/00131725.2012.682837

Richards, K. A. R., Levesque-Bristol, C., Templin, T. J., \& Graber, K. C. (2016). The impact of resilience on role stressors and burnout in elementary and secondary teachers. Social Psychology of Education, 19(3), 511-536. https://doi.org/10.1007/s11218-016-9346-x

Ruisoto, P., Vaca, S. L., López-Goñi, J. J., Cacho, R., \& Fernández-Suárez, I. (2017). Gender differences in problematic alcohol consumption in university professors. International Journal of Environmental Research and Public Health, 14(9), 1069. https://doi.org/10.3390/ijerph14091069

Sattler, S., Sauer, C., Mehlkop, G., \& Graeff, P. (2013). The rationale for consuming cognitive enhancement drugs in university students and teachers. PLoS ONE, 8(7), e68821. https://doi.org/10.1371/journal.pone.0068821

Sawhney, N., \& Bansal, S. (2013). Life satisfaction of professional college teachers in relation to their stress level. Indian Journal of Health and Wellbeing, 4(2), 272-277. Retrieved from http://www.iahrw.com/index.php/home/journal_detail/19\#list

Shen, X., Yang, Y., Wang, Y., Liu, L., Wang, S., \& Wang, L. (2014). The association between occupational stress and depressive symptoms and the mediating role of psychological capital among Chinese university teachers: a cross-sectional study. BMC Psychiatry, 14(1), 329. https://doi.org/10.1186/s12888-014-0329-1

Shou, J., Ren, L., Wang, H., Yan, F., Cao, X., Wang, H., ... Liu, Y. (2016). Reliability and validity of 12-item Short-Form health survey (SF-12) for the health status of Chinese community elderly population in Xujiahui district of Shanghai. Aging Clinical and Experimental Research, 28(2), 339-346. https://doi.org/10.1007/s40520-015-0401-9

Singh, C., Cross, W., Munro, I., \& Jackson, D. (2020). Occupational stress facing nurse academics-A mixe-methods systematic review. Journal of Clinical Nursing, 29(5-6), 720-735. https://doi.org/10.1111/jocn.15150

Skakon, J., Nielsen, K., Borg, V., \& Guzman, J. (2010). Are leaders' well-being, behaviours and style associated with the affective well-being of their employees? A systematic review of three decades of research. Work and Stress, 24(2), 107-139. https://doi.org/10.1080/02678373.2010.495262

Sun, W., Wu, H., \& Wang, L. (2011). Occupational stress and its related factors among university teachers in China. Journal of Occupational Health, 53(4), 280. https://doi.org/10.1539/joh.10-0058-OA

Tavares, J. P., Beck, C.L.C., Magnago, T. S. B. S., Zanini, R. R., \& Lautert, L. (2012). Minor psychiatric disorders among nurse's university faculties. Revista Latino-Americana De Enfermagem, 20(1), 175-182. https://doi.org/10.1590/S0104-11692012000100023

Terán, R., \& Botero, Á. (2011). El capitalismo organizacional: una mirada a la calidad de vida laboral en la docencia universitaria. Cuadernos de Administración, 27(46), 9-21. https://doi.org/10.25100/cdea.v27i46.79

The Guardian. (2019). Record levels of stress 'put teachers at breaking point'. Retrieved from https://www.theguardian.com/education/2019/nov/10/stressed-teachers-at-breaking-point-saysreport\#: :text $=$ Nearly $\% 20$ three $\% 2$ Dquarters $\% 20$ of $\% 20$ teachers $\% 20$ and $\% 2084 \% 25 \% 20$ of $\% 20$ school $\% 20$ leaders, in $\% 20 \mathrm{t}$ he $\% 20$ past $\% 20$ academic $\% 20$ year.

Urbina-Garcia, A. (2020). What do we know about University Academics' Mental Health? A Systematic Literature Review. Stress and Health, 2020, 1-23. https://doi.org/10.1002/smi.2956 
Vera, H., \& González-Ledesma, M. A. (2018). Calidad y evaluación: Matrimonio del cielo y el infierno. Perfiles Educativos, 40, 53-97. https://doi.org/10.22201/iisue.24486167e.2018.

Von Elm, E., Altman, D. G., Egger, M., Pocock, S. J., Gøtzsche, P. C., \& Vandenbroucke, J. P. (2007). The Strengthening the Reporting of Observational Studies in Epidemiology (STROBE) statement: Guidelines for reporting observational studies. Annals of Internal Medicine, 147(8), 573-577. https://doi.org/10.1016/S0140-6736(07)61602-X

Walinga, J. (2010). Stress, health, and coping. Introduction to psychology, 871-905. Retrieved from https://openpress.usask.ca/introductiontopsychology/chapter/stress-and-coping/

Ware Jr, J. E., Kosinski, M., \& Keller, S. D. (1996). A 12-Item Short-Form Health Survey: construction of scales and preliminary tests of reliability and validity. Medical Care, 34(3), 220-233. https://doi.org/10.1097/00005650-199603000-00003

Whitley, R., \& Gläser, J. (2014). The impact of institutional reforms on the nature of universities as organisations. $\begin{array}{lllll}\text { Research in the Sociology of Organizations, } & 42, & 19-49 .\end{array}$ https://doi.org/10.1108/S0733-558X20140000042000

World Health Organisation (WHO). (2017). Protecting workers' health. Retrieved from https://www.who.int/news-room/fact-sheets/detail/protecting-workers'-health

World Health Organisation (WHO). (2020). Coronavirus. Retrieved from https://www.who.int/health-topics/ coronavirus\#tab=tab_1

\section{Copyrights}

Copyright for this article is retained by the author(s), with first publication rights granted to the journal.

This is an open-access article distributed under the terms and conditions of the Creative Commons Attribution license (http://creativecommons.org/licenses/by/4.0/). 